\title{
Fibrotic submucosal scar after endoscopic submucosal dissection (ESD) or how to divert a negative adverse event into a positive endoscopic result
}

\section{(ㄷ)(1) $\odot($}

\author{
Authors \\ Marc Barthet ${ }^{1}$, Jean-Michel Gonzalez ${ }^{2}$ \\ Institutions \\ 1 Hôpital Nord, Marseille, France \\ 2 Assistance Publique Hopitaux de Marseille - \\ Gastroenterology, Hôpital Nord Chemin des Bourrelys, \\ Marseille, France \\ Bibliography \\ DOI https://doi.org/10.1055/s-0043-125327 | \\ Endoscopy International Open 2018; 06: E354-E355
}

\author{
(c) Georg Thieme Verlag KG Stuttgart · New York \\ ISSN 2364-3722 \\ Corresponding author \\ Marc Barthet, Hopital Nord - Gastroenterology, Chemin des \\ Bourrelys, Marseille cedex 20 13915, France \\ Fax: 33491968732 \\ marc.barthet@ap-hm.fr
}

The paper from K Yamamoto about application of endoscopic submucosal dissection (ESD) to reduce an inappropriate flexure of the gastric conduit opens a new door. They used the extensive fibrotic scar following ESD to reduce the gastric lumen, subsequently straightening the gastric conduit. Until now, post-ESD fibrosis was considered as the most frequent adverse event $(A E)$ leading to lumen stenosis, with incidence ranging between $68 \%$ and $90 \%$ after involving more than $50 \%$ to $75 \%$ of the esophageal circumference for instance [1 - 3]. The ability to prevent such an $A E$ is still unclear despite several available tools such as steroids with or without local injections, repeated dilatations, epithelial cell sheet translation, and biodegradable stents [4-7]. Systemic treatment with early oral steroids has been shown to be negative with gastric ESD [6]. No targeted pharmacological agents are available to decrease post-ESD fibrosis whereas biotherapy such as an anti-TNF agent exists for inflammatory diseases [6]. Other recent surgical endoscopic procedures may lead to extensive and stenotic stricture, complicating patient outcome and leading to a need for esophageal reconstruction OR endoscopic gastrojejunal anastomosis [8, 9].

The goal of the Japanese team presented by Yamamoto $\mathrm{K}$ et al was to use the extensive fibrotic scar induced by ESD for healing an abnormal flexure of the intrathoracic stomach after esogastric anastomosis. In most cases, eating troubles following esogastric anastomosis are due to anastomotic stricture, transdiaphragmatic stenosis, injury of vagal nerve resulting in pyloric spasm and gastroparesia. In the reported case, it was due to a long flexure of the ascented stomach, which acted like a $\mathrm{U}$ bend. The authors performed an $8 \mathrm{~cm}$ ESD of the normal contro-lateral gastric side to straighten the gastric conduit. Despite a perforation, 10 days later, a straight gastric conduit was dem- onstrated. Eighteen days later, the patient was eating and 35 days later, the patient was discharged from the hospital. Surgeons may argue that the 35-day hospital stay was very long, maybe longer than with uncomplicated surgery.

Healing approaches in this situation may be surgery or endoscopic alternatives such as suturing with overstitch suture devices, making a kind of sleeve gastroplasty. The authors chose to divert the fibrotic side effects of ESD to a positive result by stomach retraction. Such diverting of fibrotic adverse event after endoscopic mucosal resection (EMR) is under assessment with EMR of esogastric junction for treating gastroesophageal reflux in Japan with the so-called ARMS procedure [10]. However, even if gastric ESD is mainly performed by Japanese experts, it is a more and more widespread technique in the West with a good efficiency (98\% en bloc resection; $90-94 \%$ R0 rate) and low complication rate (perforation 1-4\%) [11]. The example of this successful case added to an ARMS procedure or endoscopic antral plasty could lead one to wonder what could be in the future, new indications. Antireflux treatment is already under assessment with extended EMR of the esogastric junction, with promising results [10]. Endoscopic sleeve gastroplasty usually is done with overstitch devices with increasing success compared to surgical sleeve gastrectomy, but one might think that multiple extended ESD could be an alternative. Endoscopic management of symptomatic diverticulum (but with high risk of perforation) or rectocele associated with dyschezia also could interesting alternatives to surgery. Development of training models and animal experiments is required before this new endoscopic management will take off. 


\section{Competing interests}

None

\section{References}

[1] Ono S, Fujishoro M, Nimi K et al. Predictors of post-operative stricture after endoscopic submucosal dissection for superficial squamous cell neoplasms. Endoscopy 2009; 41: 661-665

[2] Mizuta H, Nishimori I, Kuratani Y et al. Predictive factors for esophageal stenosis after endoscopic submucosal dissection for superficial esophageal cancer. Dis Esophagus 2009; 22: 626-631

[3] Hanaoka N, Ishihara R, Takeuchi Y et al. Intralesional steroid injection to prevent stricture after endoscopic submucosal dissection for esophageal cancer: a controlled prospective study. Endoscopy 2012; 44: $1007-1011$

[4] Pioche M, Rivory J. Prevention of esophageal stenosis after large endoscopic submucosal dissection: is there a better way to use steroids. Endosc Int Open 2015; 3: E118-E119

[5] Shibagaki K, Ishimura N, Oshima $\mathrm{N}$ et al. Esophageal triamcinolone acetonide-filling method: a novel procedure to prevent stenosis after extensive endoscopic submucosal dissection. Gastrointest Endosc 24.08 2017: doi:10.1016/j.gie.2017.08.016 (pii: S0016-5107(17) 32198-3)

[6] Kishida Y, Kakushiman N, Takizawa M et al. Effects of steroids use for stenosis prevention fter wide endoscopic submucosal dissection for gstric neoplasm. Surg Endosc 21.07 2017: doi:10.1007/s00464-0175732-5

[7] Jain D, Singhal S. Esophageal stricture prevention after endoscopic submucosal dissection. Clin Endosc 2016; 49: 241-256

[8] Gonzalez JM, Vanbiervliet G, Gasmi M et al. Efficacy of endoscopic rendez-vous technique for the reconstruction of complete esophageal. Endoscopy 2015; 48: 179-183

[9] Vanbiervliet G, Bonin E, Garces-Duran R et al. Gastrojejunal anastomosis using a tissue apposition stent : a feasibility study in live pigs. Endoscopy 2014; 46: $871-877$

[10] Inoue H, Minami H, Kobayashi Y et al. Anti-reflux mucosectomy for gastroesophageal reflux disease in the absence of hiatal hernia: a pilot study. Ann Gastroenterol 2014; 27: 346 - 351

[11] Ma MX, Bourke M. Endoscopic submucosal dissection in the West: Curent status and future directions. Dig Endosc 2017: doi:10.1111/ den.12960 [Epub ahead of print] 